\title{
IMPACTO INTERNO E INTERNACIONAL DA AMPLIAÇÃO DA UNIÃO EUROPÉIA
}

\author{
Paulo Borba Casella \\ Prolessor Associado de Direito Internacional e \\ Direito da Integração da Faculdade de Direito da \\ Universidade de São Paulo.
}

Resumo:

A ascensão de dez novos Estados-Membros da União Européia não $\dot{i}$ somente relevante para finalidades internas dentro do processo da integração da U.E. mas é também relevante para terceiros Estados, tais como o Brasil e o Mercosul; o processo de integração regional na Europa alcança um novo nivel de realização e pode ser uma oportunidade única de conduzir o legado de anos de guerra fria, uma divisão cultural de Europa "Ocidental" e de "Oriental" que data para trás ao século XVIII. A nova Europa é ainda maior desde o expansionismo do Império Romano. Um trabalho substancial e um forte comprometimento de uma geração inteira será preciso para consolidar uma Europa integrada, mas não se deve negligenciar que, além do impacto interno da integração, uma Europa integrada pode ser mais assertiva em termos de relações internacionais e pode crescer unida o bastante para ser um contrapeso aos atos isolados da política estrangeira norte-americana e às violações do Direito Internacional, atos estes executados internamente em acordos bilaterais com a Rússia, China, Índia, Brasil e Mercosul. O impacto externo da integração européia permanece contudo para ser avaliado. A questão aqui desenvolvida refere-se às normas do direito internacional e se as mesmas podem ter um impacto limitado na realidade, mas assume-se que esta é a melhor ferramenta para a regulação das relações internacionais até agora alcançadas pela humanidade.

Abstract:

The accession of ten new Member States to the European Union is not only relevant for internal purposes within the integration process in the E.U. but is also relevant for third States, such as Brazil and the Mercosur: the process of regional integration in Europe reaches a new level of achievement and can be an unique opportunity to overrule the legacy of Cold War years, dating back to a cultural division of 'Western' and 'Eastern' Europe dating back to the XVIIlth. century / the new Europe is more extended than it has ever existed since the largest extension of the Roman Empire in early Iind. century A.D. I substantial work and strong commitment from an entire generation will be needed to consolidate an integrated Europe, but it should not bi neglected that, besides and beyond the internal impact of integration, an integrated Europe can be more assertive in matters of international relations and can grow united enough to be a counterweight to the isolated hubris of United States foreign policy \& violations of international law, be it in itself or in bilateral agreements with Russia, China, India, Brazil \& Mercosur. / the external impact of 
integration in Europe remains yet to be assessed / the lesson to be drawn is the international law rules may have limited impact on reality but are the best tool for regulation of international relations so far achieved by mankind.

Unitermos: Integração; Integração Econômica; Integração Regional; União Européia; Relações Internas e Externas da União Européia; Mercosul.

Keywords: Integration; Economic Integration; Regional Integration; European Union; Internal and International Relations of the European Union; Mercosur.

\section{Preliminar}

Desde 1993, quando pela primeira vez foi lecionado na Faculdade de Direito da Universidade de São Paulo a disciplina Direito da Integração, inicialmente como disciplina optativa e logo a seguir como obrigatória, vem mudando substancialmente a percepção da necessidade e do alcance da disciplina e do estudo do fenômeno da integração regional sob a ótica do Direito Internacional. Torna-se indiscutivel não ser este tema passageiro nem modismo intelectual, mas assunto que terá de ser estudado e levado em conta, tanto no âmbito do Direito Internacional como um todo, bem como em relação ao Direito Econômico e outros ramos dos direitos internos, inevitavelmente afetados pela integração regional.

A evolução recente da União Européia alcança patamar de integração que muito da dimensão interna do fenômeno de mercado integrado, faz surgir protagonista de primeira grandeza, apto a atuar de modo relevante no cenário internacional mais vasto. Quanto isso se efetivará em futuro próximo ainda está para ser determinado.

A União Européia está fazendo ampliação em $1^{\circ}$ de maio de 2004, na qual ingressam de uma só vez dez novos Estados.

A ampliação, em $1^{\circ}$ de maio de 2004 , é a mais abrangente, para não dizer a mais espetacular até aqui encetada, bastando considerar que todas as anteriores, somadas, agregaram aos seis integrantes originais, desde o início do 
processo de integração regional, em 1951, outros nove, em sucessivas vagas, nos anos 70,80 e 90, e, agora, dez países entram de uma só vez. Este avanço da integração regional altera o mapa político, o funcionamento econômico e pode significar maior amplitude na atuação estratégica internacional da Europa em futuro próximo.

O processo de integração econômica da Europa combina progressivo aprofundamento interno e sucessivas ampliações, passando dos primeiros seis, a quinze, em quatro ampliações sucessivas, e chega a 25 Estados na União Européia. Este número pode e deve aumentar nos próximos anos, pois existem candidatos na lista de espera, como Romênia e Bulgária, que devem estar prontos para ingressar em 2007 Depois destes, outros países candidatos sequer escondem sua ansiosa expectativa de adesão ao bloco.

O processo exigirá o trabalho de uma geração para poder pretender avançar com a presente ampliação rumo à efetivação da idéia de Europa, unida e sem fronteiras, pondo "fim à secessão da Europa" dividida entre ocidente e mundo comunista, nos quarenta anos da Guerra Fria, bem como superando a anterior distinção entre Europa "ocidental", contrapondo-se a outra "oriental" que remonta aos iluministas franceses do sćculo XVIII, e perpetuou-se, mostrando os limites do projeto, porquanto a equiparação em conjunto intugrado de iguais, exige parâmetros de operacionalidade tão elevados que exigirão tempo e esforços consideráveis para se completarem, de tal extensão e profundidade que mesmo a simples apresentação esquemática ilustra de modo contundente:

A idéia de Europa, surge como contraposição a ameaças externas, antes de se afirmar como conteúdo positivo e específico . de afirmação de identidade européia -, conterá os elementos do futuro, na medida em que se completem as etapas fundamentais do processo de integração, para permitir a consolidação interna desta. em escala suficiente para se afirmar como potência de primeira grandeza. em âmbito internacional amplo. Pode a Europa integrada ser elemento de mudança do presente desequilibrio de forças na ordem internacional, que pauta as relações internacionais capengas, sem dois modelos que se contrapunham, como ocorria desde os "bons velhos tempos" da guerra fria, substituída por hegemonia 'unipolar' tacanha, exercitada antes como extensão de política interna (sujeita às injunções e condicionamentos desta), mais que verdadeira visão de politica internacional. Esta não é somente questão de secos e molhados, mas pode mudar a face do mundo. fazendo deste algo melhor. 
Pode a Europa integrada ser contraponto ao desequilíbrio da ordem atual?

A Europa efetivamente integrada pode se projetar como potência de primeira grandeza nos próximos anos e isso pode ser elemento crucial e saudável, para criar nova ordem mundial, um pouco mais segura? Talvez. Essa potência, a União Européia, se conseguir manter grau mínimo de projeção externa de sua unidade interna, mediante política externa comum pode celebrar acordos bilaterais com Rússia e Japão, como também com o Brasil, o Mercosul, ou ainda Índia ou China, e mudar substancialmente o atual distanciamento, que gera distorções insuportáveis, e de descaramento poucas vezes aproximado, entre as posições de força e do direito, por parte dos Estados Unidos da América.

Trata-se de visualizar a extensão da mutação do mapa da Europa, mediante o ingresso de dez novos Estados. Vem somar-se aos quinze, desta vez: Chipre, Eslováquia, Eslovénia, Estônia, Hungria, Letônia, Lituânia, Malta, Polônia e República Checa. Muda substancialmente o desenho da Europa, com a expansão da Europa integrada.

Veja-se a continuidade à linha que já se desenhara desde a adesão e ingresso da Finlândia, onde a fronteira da Europa integrada se fará com a Federação Russa, desde o Mar de Barents, no Círculo Polar Ártico, e prosseguirá junto às fronteiras da Bielorússia e Ucrânia, infletirá rumo ao mar Cáspio, depois que se der o ingresso de Romênia e Bulgária, por ora infletindo rumo ao mar Adriático. Mais a "leste" ficarão, por enquanto Grécia e Chipre, descontados o "enclave" de Kaliningrado (a Königsberg, dos tempos do filósofo Emmanuel Kant) e os renitentes, como Noruega e Suiça, que já recusaram convites anteriores.

É enorme o desafio geográfico e operacional, para assegurar a efetividade e qualidade de funcionamento em toda a extensão da Europa unificada.

Europa sem fronteiras, em tal extensão, nunca existiu em todo o curso da História, mesmo se considerarmos a extensão máxima que alcançou o Império Romano, sob Trajano, pois a fronteira que separava a Europa romana, o "limes", 
marcava o fim oriental das terras do Império e início dos territórios germânicos, no centro da Europa de hoje e ao norte, a muralha de Adriano basicamente separava o norte da Inglaterra da Escócia.

A U.E. com 25 Estados irá além de qualquer projeto anterior de vida econômica sem fronteiras ... barreiras culturais levam mais tempo para ser neutralizadas.

Os dez novos Estados-membros da U.E. agregarão 75 milhões de habitantes ao conjunto e trarão consideráveis desafios, para assegurar o ajuste do padrão de vida dos cidadãos e dessas economias aos parâmetros europeus. Pouco mais da metade dos novos cidadãos europeus (cerca de 39,5 milhões) serão poloneses.

A questão das línguas se torna o grande desafio operacional.

Vem somar-se às doze linguas oficiais da U.E. mais nove novas: esloveno, polonês, húngaro, checo-eslovaco (conte-se uma ou duas línguas, pois. se de um lado, as diferenças entre checo e eslovaco podem ser materialmente menores, cultural e politicamente são acirradas, por séculos de história e o passado recente), estoniano, letão, lituano (pois os três bálticos, somando seis milhões de pessoas. trazem sua língua nacional cada um. e dificuldade de comunicação entre si), maltês (este será espécic de curiosidade como o é já o gaélico, pois a segunda língua oficial do país, o inglês acabará sendo a lingua de uso corrente).

A questão das línguas na Europa integrada já era complexa, operando em doze línguas oficiais, mas vinha mantendo ao menos nominalmente a igualdade entre estas. Tal pretensão torna-se inviável com a adição de mais nove, onde os novos países irão potencializar problemas já existentes.

As linguas oficiais comunitárias multiplicam os problemas, pois todas as leis (rugulamentos, diretivas, e todas as demais modalidades de criação de normas e pareceres) e atos administrativos, emanados dos órgãos comunitários, todas as decisões judiciais dos tribunais europeus (a Corte Furopéia e o Tribunal de Primeira Instância), a publicação do Diário Oficial da União Européia e todos os debates no Parlamento e órgãos colegiados (excetuados os casos nos quais as comissões adotam 
e trabalham em língua dita de trabalho) terão de transcorrer em todas as línguas oficiais.

Acirrar-se-á, desse modo, inevitavelmente, o debate a respeito dos idiomas, com a controvertida questão das linguas oficiais e linguas de trabalho, questão das mais espinhosas, que já coloca múltiplos problemas operacionais na Europa, com doze linguas oficiais e ficará potencializado, com a ocorrência de 21 idiomas oficiais. Verdadeira torre de bubel para ser administrada, sempre correndo risco de descontentar uns e outros.

Não menos espetaculares todas as mudanças estruturais dos sistemas legais, políticos, administrativos. judiciais, previdenciários.

Mudanças estruturais dos sistemas legais, políticos, administrativos, judiciais, previdenciários serão necessários e terão de ser dimensionados. A mutação do conceito formal de soberania, em função da integração, longe de ser antagônica, enseja harmonização em graus cada vez mais extensus de operacionalidade. justamente visando assegurar a paz. entre os povos em estados de direito. Esse patamar de operacionalidade da Europa integrada será a tarefa dos próximos vinte ou trinta anos, a obra de uma geração.

Ampliações da U.E. já ocorreram diversas, mas nenhuma das anteriores teve alcance e sentido histórico e estratégico comparáveis à adoção de unidade político-administrativa, jurídico-econômica e sócio-cultural em relação a conjunto de 25 Estados, englobando quase todos os países europeus, com exceção da Rússia, da antiga Iugoslávia, menos a Eslovénia, que se integra ao bloco europeu, e dos referidos recalcitrantes, Noruega e Suiça, que puderam, mas não quiseram.

Quanto tempo será necessário para a implementação da integração?

lista etapa da integração econômica transforma radicalmente o mapa político da Furopa, o conteúdo econômico e social interno além de marcar o futuro da empreitada de integração regional. Os reflexos externos dessa ampliação devem ser, também, considerados: antes de qualquer outra, mostra-se a necessidade de 
informação a respeito desses dez Estados, e avaliação do impacto dessas adesões, não-somente em relação à própria União Européia, como em relação a terceiros Estados.

A atual ampliação pode e deve ser vista também como continuidade do projeto de pôr termo às guerras intra-européias da era dos nacionalismos, e permitir ao continente assumir sua tarefa de cuidar de si próprio e afirmar seu sistema de valores em escala mundial, aplicando os três critérios estabelecidos por ocasião da reunião do Conselho Europeu de Copenhagen, em junho de 1993: instituições democráticas, economia de mercado viável e instituições aptas a assumir as obrigações decorrentes da adesão à União, mediante a implantação do acervo comunitário.

A adesão de dez novos Estados terá alcançado mais que qualquer das tentativas hegemônicas, tanto na extensão e espera-se também na duração

As tentativas hegemônicas de integração forçada, sob a égide de pais ou ditador, foram de vida curta e resultados desastrosos, tanto sob Napoleão, no início do século XIX, como sob Hitler, no final da primeira metade do século XX.

Alguns desafios vem para o interior da União Européia:

Chipre traz conflito civil para dentro da Europa integrada;

a espera da Turquia não somente pelo pequeno 'detalhe geográfico' mas histórica e culturalmente como força estranha em relação à Europa, embora vizinha. Coloca problemas quanto a se e quanto pode ser considerada européia, e essa questão não comporta respostas fáceis, por não serem estas nem somente juridicas, nem políticas, nem culturais, mas congregando elementos de todas, agravados pela condição das minorias 
e violações de direitos humanos de curdos e opositores do regime;

a entrada dos três bálticos (Estônia, Letônia e Lituânia) resolve injustiças do passado, quanto a serem estes estados europeus e terem vocação européia, mas deixa em aberto a espinhosa questão da região de Kaliningrado/Königsberg este pedacinho avançado da Rússia, desde o final da Il Guerra Mundial, com suas raízes históricas alemãs - a cidade de KANT pode ter estatuto europeu específico. adaptado ao seu caso?;

países como a República Tcheca e a Hungria sempre estiveram inseridos no contexto europeu, ao longo dos séculos, e somente foram 'neutralizados' na sua vocação e atuação européia durante os quarenta anos da guerra fria, inclusive com o poder militar soviético, invadindo $\mathrm{e}$ sufocando rebeliões libertárias, em Budapeste, em 1956 e em Praga, em 1968;

a Polônia tem se mostrado, mesmo antes da adesão, pouco propícia a acomodar-se em relação aos demais países e pode estar consciente de seu glorioso passado como potência na Europa central, no século XIV, em união à Lituânia? a atitude polonesa em relação a crise iraquiana de 2003 pode ser exemplo ilustrativo dessa tendência;

a questão de possível acordo bilateral da União Européia e Rússia, além do interesse direto para ambos os lados, pela dimensão das fronteiras comuns, pelos volumes de comércio bilateral, pode também ser alternativa estratégica da maior magnitude internacional;

o tamanho e o perfil da Europa integrada e seu papel futuro, no contexto mundial - com condição de superar as divisões e suplantar as dissensões intra-européias pode ser esta força considerável, no jogo internacional. seja no âmbito interno da U.E. seja em relação ao futuro e papel 
da OTAN, a Organização do Tratado do Atlântico Norte e atuação possível desta;

a Europa integrada pode ser fator de equilibrio internacional, contrapondo-se ao atual vazio estratégico, onde "reinam mas não governam" os Estados Unidos da América, e terão de mostrar se estão ou-não capacitados para exercer liderança mundial, que não seja legitimada somente pelo uso da força militar e econômica.

Avaliação de conjunto.

Pouco se parece estar atentando para a importância desta ampliação. $O$ trabalho será extenso e demorado, mas as bases desta integração foram sendo cuidadosamente preparadas. Mais que os ajustes burocráticos e funcionais, pode-se pensar em alguns dados de conjunto e impacto. interno e internacional.

Di $<$ o ditado "Roma não foi feita cm um dia" e a I:uropa integrada, depois de cinqüenta anos é canteiro de obras. com consideráveis sucessos e alguns fracassos arquivados. Completar a integração será a obra de, pelo menos, mais uma geração, como aponta o projeto de constituição da Europa.

A tarefa é enorme e exigirá compromisso firme em favor da construção dessa Europa que resgata e deita abaixo a divisão entre Europa "ocidental" e "oriental" que, ademais, enquanto conceito político, já estava ultrapassado, e deve ser preterido em favor de conceito geograficamente neutro e politicamente correto de "Europa central"

A linha divisória entre Europa "ocidental" e "oriental". agravada pela Guerra Fria e a divisão ideológica - a "cortina de ferro" na imagem de Winston Churchill - perdura do final da IJ Guerra Mundial até o "ano admirável" de 1989. Pode-se dizer que. na verdade, precede este conflito em cerca de duzentos anos, tendo sido formulada claramente a linha divisória na era dita do Iluminismo, pelos enciclopedistas franceses. Dois mundos paralelos, com tantas semelhanças quanto diferenças.

Os paises que passaram quarenta anos submetidos à esfera de influência soviética estão resgatando em ritmo acelcrado suas identidades nacionais e suas vocações européias. Isso vem resgatar passado que remonta ao término da I Guerra 
Mundial, ou muito antes. A construção de economias de mercado e estados democráticos de direito, eliminando as heranças autoritárias é aspecto dos mais fascinantes dessa presente alteração.

Dentre as lições a serem tiradas desse aprendizado, muitas terão aplicação na Europa que se quer ir integrando, percebendo que é um processo, que se há de ir implantando progressivamente. Além das lições de uso interno, algumas podem ser projetadas, comparativamente, para outros quadrantes. Como, por exemplo, em relação aos países latino-americanos, onde se tende a ver semelhanças, esquecer diferenças e reduzir eficiência dos esforços de construção de espaços integrados, por negligenciar estas diferenças, que não abordadas nem enfrentadas seria e estruturalmente, perpetuam-se, intocadas.

A convivência institucionalizada entre quase todos os povos europeus, do Atlântico até a fronteira russa será algo nunca antes em tal dimensão experimentado. A situação dos "recalcitrantes" que escolheram permanecer fora da empreitada européia (leia-se, Noruega e Suíça) será de esperar para ver, porquanto em nome e visando proteger bem estar do qual agora gozam, escolheram permanecer $a$ latere, mas o tempo dirá se esta foi ou-não a escolha mais adequada.

Essa convivência institucionalizada, resgatando séculos de história, pode permitir a colocação de bases mais amplas para a Europa integrada, desde que se consiga absorver a integração, em toda a extensão de esforços e sacrifícios que será necessária. É preciso ter consciência da extensão destes. São enormes as mudanças culturais, políticas, econômicas e jurídico-institucionais que serão necessárias, e o impacto destes na prática sempre se fará sentir. e suscitará críticas e lamentações, por mais cuidadosos e abrangentes que sejam os estudos preparatórios e relatórios explicando os passos e necessidades para essa equiparação de cada um dos novos Estados, a partir da adesão à União Européia.

Faça-se paralelo que pode ser ilustrativo: a absorção, pela República Federal da Alemanha, dos novos estados federados (neue Bundesländer) e o impacto deste processo sobre o conjunto da vida nacional, política e economia alemã. exigiram mais de dez anos de trabalho, com maciços investimentos, refazendo literalmente desde a base, toda a infra-estrutura e as instituições desse território que durante quatro décadas (de 1949 a 1989) compôs a República Democrática Alemã. Foi enorme a tarefa. Astronômico o custo. Crucial a "exportação" de quadros - juizes, funcionários públicos, tecnocratas - para "passarem a limpo" esse país falido, poluido, 
empobrecido, que foi transformado desde a base, com estradas, investimentos em resgate do meio ambiente e adoção de tecnologias e insumos que menos agredissem o meio ambiente e tivessem mais eficiência, até que começassem a aparecer resultados. Imagine essa "repaginação" em escala européia, abrangendo os dez novos Estados? Enorme a tarefa e igualmente considerável o potencial de investimentos e crescimento, nos próximos quinze a vinte anos.

A absorção dos dez novos Estados exigirá esforço proporcionalmente à escala dessa transformação, até que se alinhem pelo mesmo exato patamar: uma geração talvez seja pouco para essas tarefas e absorver as mudanças.

Curiosamente em relação à maioria destes dez. Estados, antigos satélites do bloco soviético, ocorrerá a passagem de condição de soberania "tutelada", ou fictícia, que lhes marcou a história da segunda metade do século XX, como dolorosamente ilustram as revoltas libertárias, esmagadas pelas tropas do Pacto de Varsóvia, na Hungria, em 1956, na então Checoslováquia, em 1968, para a condição de Estados que delegarão parcelas consideráveis de suas soberanias para as autoridades comunitárias. De Moscou a Bruxelas, o jugo há de ser mais leve, de natureza diversa e não-somente orientado em uma direção, como teria sido, para todos os demais integrantes do bloco soviético, tendo ênfase em construção de todo comum, de níveis de desenvolvimento regional tendendo a equiparar-se, com forte ênfase em políticas econômicas comuns, moeda única e todo o arsenal de medidas de construção progressiva dessa Europa integrada, mais ampla que até hoje se experimentara. Curiosamente a Polônia vem se mostrando mais exigente do que seria de se esperar.

A integração destes dez novos Estados, com todos os desafios e tarefas que terão de ser enfrentados traz tarefa pelo menos para os próximos dez, mais provavelmente vinte ou trinta anos, até que tenham sido completados. Vale lembrar que o conjunto é dinâmico e não estático, ou seja as mutações são concomitantes, sucedem-se mas mais freqüentemente intercalam-sc e influenciam-se reciprocamente.

A passagem dos atuais quinze para 25 Estados na U.E. além da espetacular ampliação geográfica, é igualmente espetacular, pelos desafios 
operacionais colocados. Politicamente a Europa integrada será algo distinto do que até agora se conheceu e experimentou. O elemento político poderá alcançar durabilidade e resistência na medida em que se acompanhe da eficiência econômica. Essencialmente tratar-se-á de alcançar e manter esse desafio da eficiência econômica para todos os paises envolvidos nesse esforço comum.

A partir dos eixos político e econômico, outros podem ser destacados, em eixos principais de operacionalidade: as línguas, a aplicação do direito comunitário pelas instâncias judiciais e administrativas nacionais.

Questão inevitavelmente espinhosa e politicamente explosiva, que terá de ser enfrentada, as línguas oficiais e sua operacionalidade, nessa Furopa integrada. De um lado, a necessidade de absorção de todas estas novas línguas oficiais, isso considerando tanto as centenas de milhares de páginas de todo o "acquis communautaire" (ou seja o conjunto de todos os textos de direito originário e derivado. todas as decisões judiciais dos tribunais europeus, que compõem a jurisprudência comunitária, e demais elementos administrativos) como, de outro lado, em relação a toda a nova produção dessa babel contemporânea, no dia-a-dia da Europa integrada, com sessões do Parlamento Europeu, suas comissões e demais colegiados que operam em todas as línguas oficiais. com debates ocorrendo em tradução simultânea.

Não menos extenso e ingente o trabalho de construção de parâmetros de interpretação e aplicação do direito comunitário pelas instâncias judiciais e administrativas nacionais, de modo a assegurar que as mesmas normas sejam da mesma forma entendidas e postas em prática, em todas as instâncias judiciais e administrativas, em todo esse vasto conjunto da Europa integrada, em toda a sua extensão, com as enormes diferenças entre regiões. Nesse ponto, a completa disponibilidade de todo o ordenamento jurídico original e derivado, como toda a jurisprudência dos tribunais europeus (CJCE e Tribunal de Primeira Instância). em cada uma das linguas oficiais, são cruciais para que se possam estudar e conhecer as normas e como haverá de dar-se a sua aplicação em todos os 25 Estados da U.E.: sem dispor dos textos legais, não haverá modo de assegurar esse processo de construção dos parâmetros de interpretação e aplicação uniformes do direito uniforme.

Em suma, trata-se de, depois de celebrar o acontecimento da assinatura dos atos de adesão, sua ratificação, segundo as regras estipuladas pelos direitos internos, e entrada em vigor. em cada um dos dez novos, ir a cada dia fazendo que se 
materialize a adoção do patamar de operacionalidade do direito comunitário pelas instâncias judiciais e administrativas nacionais em todos e cada um destes Estados: mais uma vez, será, ao menos, o trabalho de mais uma geração.

Cada uma das administrações nacionais passa a estar vinculada e obrigada a aplicar em todas as questões com dimensão pertinente à integração, os textos e critérios de natureza comunitária, observando os parâmetros que norteiam a aplicação desse ordenamento, em busca do patamar de otimização do funcionamento das instituições nacionais c comuns.

Cada um dos tribunais nacionais passa a estar vinculado e obrigado a aplicar em todas as questões com dimensão pertinente à integração, os textos e critérios hurmenêuticos de natureza comunitária, observando os parâmetros que norteiam a aplicação desse ordenamento, em busca do patamar de aplicação uniforme do direito comum e eliminando pontos de conflito na operação entre institutos do ordenamento nacional e comuns.

As presentes observações de caráter necessariamente esquemático, dada a amplitude da transformação que estará em curso e o conjunto de seus desdobramentos político-econômicos como legais-institucionais e sócio-culturais, exigirão considerável trabalho de análise e reflexão, a estender-se multidisciplinariamente por muitos anos, não pode ser esgotado, em momento no qual tantas das componentes todavia sequer são conhecidas, mas será. neste ano de 2004 e nos seguintes, a mais extensa e mais relevante transformação do contexto europeu, diretamente atuante nesse processo de adesão desses dez novos Estados, com a implementação de todos os mecanismos de atuação da Europa integrada, no plàno político, institucional e legal, como no cenário internacional, mudando o equilibrio de forças mundial.

Europa integrada e contexto internacional.

A mutação substancial do mapa e do futuro político da Europa integrada não é somente assunto interno. Parecemos estar ultimamente acometidos de miopia que nos faz enxergar sobretudo os desmandos da política interna, bem como os estragos da desastrada invasão e ocupação do Iraque pela coalizão liderada pelos Estados Unidos, bem como pelas violações do Direito Inturnacional pela política israelense em relação aos palestinos, esquecendo-nos de quanto o mundo está 
mudando a partir da consolidação da integração na Europa e esta mutação tem igualmente dimensão internacional que nos afeta e interessa diretamente no Brasil e no Mercosul.

$O$ atual contexto mundial padece de todos os males herdados do passado: a Guerra Fria deu lugar ao conflito de civilizações, agravado pela falta de visão e conhecimento de detentores de poder, e pode ser aperfeiçoado mediante a multiplicação de pólus: potências grandes e médias que venham contrabalançar os desequilibrios do mundo presente.

A presente ampliação da U.E. não pode nem deve ser vista somente como assunto interno europeu. Seria erro considerável esquecer a enorme dimensão internacional de tal mudança.

Esse quadro pode completar-se com tratados abrangentes e eficazes que venha a União Européia a celebrar com Rússia. Japão e da América Latina. como seria de interesse e relevância direta para o Brasil e para o Mercosul. Algo que se vem preparando há alguns anos, acordo comercial abrangente entre U.E. e Mercosul - algo nos moldes do que esta já fez com o México, e aprofundando o acordo-quadro U.E. Mercosul (assinado em Madri, em 15 de dezembro de 1995) pode ter alcance e desdobramentos estratégicos muito além do cue já se percebe do ponto de vista estritamente comercial.

As mudanças além do efeito interno e direto para os países engajados na construção da Europa integrada podem servir como laboratório de experimentação da convivência multilateral institucionalizada entre Estados. E quem sabe preparando o caminho para o futuro, em relação aos modelos obsoletos de pretensão de soberania mais ou menos absoluta dos Estados. dando lugar à percepção de interesses comuns e valores compartilhados, com base nos quais possam grupos de Estados unir-se em espaços mais ou menos coesamente integrados. nos planos político-econômico-legal. para construção de economias de escala e neutralização de inimizades regionais, além de permitir contrabalançar desequilíbrios mundiais.

Podemos e devemos continuar acreditando, como Hugo Grócio, no início do século XVII, que a ordem internacional é falível e tem limites, mas é passível de aperfeiçoamento progressivo, tanto mais porque esta é a 
menos ruim das alternativas de ordenação da convivência entre Estados.

A experiência de construção de Europa integrada, no interior da qual os conflitos armados sejam neutralizados, mediante a institucionalização de mercado e interesses econômicos comuns está fazendo mais pela paz mundial que todos os esforços hegemônicos ou discursos em outros campos alcançaram em eras precedentes, deixando pra trás seiscentos anos de guerras européias, para instituir regime comum para cidadãos e administrações, além da economia, da qual a conquista mais expressiva foi a implantação de moeda comum, ampliando-se para outros campos, com destaque para o crescente alinhamento de políticas sociais e condição de cidadania da União.

Não somente novo e grande mercado, mas também pode estar surgindo nova potência mundial. Pode esta ser alternativa saudável para o equilíbrio e funcionamento do mundo atual.

São Paulo, março de 2004. 